\title{
Analysis of MMP-3 polymorphism in osseointegrated implant failure
}

\author{
Francielle Boçon de Araujo Munhoz ${ }^{1}$, Paula Regina Bach Nogara², Francisco Rafael da Costa Junior ${ }^{3}$, Filipe Polese \\ Branco4, Maria Cristina Leme Godoy dos Santos ${ }^{5}$ \\ 1, 2, 3PhD student Department of Cell Biology, University Federal of Paraná, Curitiba, PR, Brazil \\ ${ }^{4} \mathrm{PhD}$ Professor Faculty Avantis of Balneário Camboriú, Balneário de Camboriú, SC, Brazil \\ ${ }^{5} \mathrm{PhD}$ Professor Department of Cell Biology, University Federal of Paraná, Curitiba, PR, Brazil
}

Received for publication: February 15, 2017 Accepted: June 20, 2017

Correspondence to: Francielle Boçon de Araujo Munhoz Av. Cel Francisco $\mathrm{H}$ dos Santos, s/n, Jardim das Américas, 81531-990, Curitiba - PR, Brazil.

Phone: +55-041-33611598

Fax: + 55-041-3266-2042

E-mail: francielle.bocon@hotmail.com

\begin{abstract}
Polymorphisms in matrix metalloproteinases (MMPs) genes have been associated with several pathologies, including dental implant loss. MMP-3 is crucial to the connective tissue remodeling process. The objective of this study was to investigate the possible relationship between -1612 MMP-3 polymorphism and the early implant failure. A sample of 240 non-smokers was divided: test group 120 patients with one or more early failed implants and control group 120 patients with one or more healthy implants. Genomic DNA from oral mucosa was analyzed by PCR-RFLP. No association of early implant loss with genotypes and alleles of the -1612 polymorphism in MMP-3 were found by the Chi-squared test. Only the presence of the -1612 polymorphism of MMP-3 is not a genetic risk factor for early loss of implants.
\end{abstract}

Keywords: Polymorphism. Metalloproteinase. Implant loss. Risk factor.

\section{Introduction}

Dental implants have become important therapeutic option and are now the most chosen option for oral rehabilitation in edentulous and partially dentate patients because of its high predictability and success rate.

However, the literature reported global failure rates of $1.9-3.6 \%{ }^{1}$, despite adequate surgical and medical treatment. Several risk factors, like osteolysis, medical preconditions, poor bone quality, smoking, one-or-two-step surgery, have been proposed in literature $^{2}$. In addition studies have demonstrated that implant material is an important determinant of treatment outcome ${ }^{3}$. The fact that only in a minority of titanium particles induce inflammation and osseo-disintegration, suggests an important role of host factors, in particular the immune response to titanium.

In addition this, multiple implant failures in the same patient, the cluster phenomenon, indicate that individual's host response play a significant role in the implant loss ${ }^{4}$. Gene polymorphisms are a biologically normal condition which individuals may exhibit genetic variations, which may increase their susceptibility to a certain disease. Polymorphisms in matrix metalloproteinases (MMPs) genes have been associated with a number of pathologies, including dental implant loss ${ }^{5-7}$.

Matrix metalloproteinases (MMPs) are the major class of enzymes capable of cleaving all extracellular matrix substrates, including collagens, fibronectin, laminin, vitronectin and proteoglycans8, and are involved in physiological and pathological 
processes. MMPs regulate a variety of cell behaviors such as cell proliferation and motility, apoptosis, angiogenesis, effects on the immune system and host defense, and modulation of the bioactivity of chemokines ${ }^{8}$. In fact, MMPs are expressed by the major inflammatory and connective tissue cells in response to specific stimuli of remodeling, including implant osseointegration. Besides, the literature demonstrated that MMP levels in peri-implant sulcular fluid are high, including MMP-139.

MMP-3, or stromelysin-1, have broad substrate specificity and have an important role in remodeling of connective tissue. It participated of turnover of diverse extracellular matrix components, including non-fibrillar collagens, laminin, proteoglycan and fibronectin. It also activates other MMPs, such as MMP-1, MMP-2 and MMP-9; as well as its own proenzyme ${ }^{10,11}$. MMP-3 can be produced by fibroblasts, macrophages, neutrophils, chondrocytes, synovial cells, and smooth muscle cells and can be induced in reaction to local stimulation such as mechanical loading ${ }^{12}$ and inflammation ${ }^{13}$.

The MMP-3 gene, located on chromosome 11, has functional polymorphisms in the promoter region -1612 characterized by containing either five or six consecutive adenines $(5 \mathrm{~A} / 6 \mathrm{~A})$ and has been associated with various pathologies including periodontal disease ${ }^{14}$.

In present study the purpose was to investigate the relationship between -1612 polymorphism in the MMP-3 gene and early failure of osseointegrated oral implants.

\section{Material and Methods}

\section{Study population}

A sample of 240 non-smoking subjects, $>18$ years of age, were recruited for study from the patient pool at the Dental Clinics of the Faculty of Dentistry of Piracicaba - University of Campinas (UNICAMP), Piracicaba, São Paulo, Brazil, Latin American Institute for Dental Research, Curitiba, Paraná, Brazil and private implantology clinical in São Paulo, Bahia, Paraná - Brazil. The rate of implant loss of these centers was less than $3 \%$. All patients were advised previously about the nature of the study and signed a consent form within a protocol approved by an Institutional Review Board (Ethical Committee in Research at FOP-UNICAMP, protocol 006/2002). This study has followed the guidelines of Helsinki Declaration.

All subjects were in good general and oral health and did not have any of the following exclusion criteria: a history of diabetes or osteoporosis, hepatitis or HIV infection, immunosuppressive chemotherapy, history of any disease known to severely compromise immune function. It also excluded patients that submitted a precocious prosthesis load or regenerative surgery, such bone grafting, and have had postsurgical complications, such as infection. All patients have a transgingival healing concept performed..

The groups were matched by gender and age; with $66 \%$ female and mean age 49 (range 18-80). The groups were matched by implant position; with $61 \%$ mandibular region and $67 \%$ posterior region. Subjects were divided into two groups: control group, 120 patients with one or more healthy implants for a minimal period of 1 year, and test group, 120 patients that had suffered one or more early implant failures, considered when presented mobility and/or pain before or during the abutment connection and needed to be removed.

\section{Genotyping}

DNA from epithelial buccal cells was extracted using the procedure described by Aidar and Line ${ }^{15}$. DNA concentration (ng/ $\mu \mathrm{L}$ ) was estimated by measurements of optical density $260 / 280$ $\mathrm{nm}$ ratio greater than 1.9 .

The MMP-3 genotype was determined by the PCRRFLP assay. The PCR primers used for amplifying the MMP-3 polymorphism were: forward primer 5'-GGTTCTCCATTCCTTTGATGGGGGGAAAgA-3' and reverse primer 5'-CTTCCTGGAATTCACATCACTGCCACCACT-3'. The forward primer for amplifying the MMP-3 fragment was mutated from $A$ to $G$ at the second nucleotide close to the 3' end to create a Tth111I recognition site in the case of a $5 \mathrm{~A}$ allele. PCR were carried out in a total volume of $10 \mu \mathrm{l}$, containing 400ng genomic DNA, $5 \mu 1$ of Taq Green Jumpstar Taq ReadyMix (Amersham Pharmacia-Biotech, Uppsala, Sweden) and $200 \mathrm{nmol}$ of each primer. A $6 \mu \mathrm{l}$ aliquot of PCR products were then digested with 1 unit of Tth $111 \mathrm{I}$ enzyme at $37^{\circ} \mathrm{C}$ overnight. The total amount aliquot of the digest was electrophoresed on a $10 \%$ vertical non-denaturing polyacrylamide gel at $20 \mathrm{~mA}$. The gel was stained by ethidium bromide.

\section{Statistical analysis}

Mann-Whitney $U$ test was used to determine any significant differences between ages and gender. The significance of the differences in the observed frequencies of polymorphism between both groups was assessed using the Chi-squared test with $\mathrm{p}<0.05$ indicating statistical significance. The program ARLEQUIN (v. 2.0 - Schneider et al., 2000) ${ }^{16}$ was used to verify the Hardy-Weinberg equilibrium in the studied sample. To verify statistical power of our sample, we used G*POWER software.

\section{Results}

The primers used were efficient to amplify the fragment and the Tth111I enzyme digestion cleaves the PCR products in two fragments when the polymorphism site contained the $5 \mathrm{~A}$ allele. Electrophoresis produced DNA bands of 97 and $32 \mathrm{bp}$ for $5 \mathrm{~A}$ alleles and a band of $129 \mathrm{bp}$ for $6 \mathrm{~A}$ alleles, whereas the heterozygote displayed a combination of both alleles $(129,97$ and $32 \mathrm{bp}$ ).

Genotype distribution was in Hardy-Weinberg equilibrium. Statistical power estimation for our sample showed $99 \%$ for association detection.

The statistical analysis did not show significant differences in the alleles and genotypes $(p=0.2)$ of the $-16125 \mathrm{~A} / 6 \mathrm{~A}$ in MMP-3 between the two sample groups. The result shows that in both groups was the higher frequency of allele 6A and the 5A/6A genotype (Table I). 
Table 1 - Distribution of the MMP-3 allele and genotype in the control and test group.

\begin{tabular}{|c|c|c|c|c|c|c|}
\hline \multirow[t]{2}{*}{$\begin{array}{l}\text { MMP-3 } \\
(-1612) \\
\end{array}$} & \multicolumn{2}{|c|}{$\begin{array}{l}\text { Control } \\
\text { Group }\end{array}$} & \multicolumn{2}{|c|}{$\begin{array}{c}\text { Test } \\
\text { Group }\end{array}$} & \multirow{2}{*}{$\begin{array}{c}\text { Chi- } \\
\text { Squared }\end{array}$} & \multirow[t]{2}{*}{ OR $(95 \%$ IC $)$} \\
\hline & $n$ & $\%$ & $\mathrm{n}$ & $\%$ & & \\
\hline Allele & \multicolumn{2}{|c|}{$n=240$} & \multicolumn{2}{|c|}{$n=240$} & & \\
\hline $5 A$ & 102 & 42.5 & 115 & 48.0 & $p=0,24$ & $0.80(0.56-1.12)$ \\
\hline $6 \mathrm{~A}$ & 138 & 57.5 & 125 & 52.0 & & \\
\hline Genotype & \multicolumn{2}{|c|}{$n=120$} & \multicolumn{2}{|c|}{$n=120$} & & \\
\hline $5 \mathrm{~A} / 5 \mathrm{~A}$ & 22 & 18.3 & 24 & 20.0 & & \\
\hline $5 \mathrm{~A} / 6 \mathrm{~A}$ & 58 & 48.3 & 67 & 55.8 & $p=0,23$ & $0.89(0.47-1.70)$ \\
\hline $6 \mathrm{~A} / 6 \mathrm{~A}$ & 40 & 33.3 & 29 & 24.2 & & \\
\hline
\end{tabular}

\section{Discussion}

Biological, microbiological and biomechanical factors can be accredited implant loss, however the exact cause and mechanism of early implant failure are still uncertain. An abnormal immune-inflammatory response, involving fibroblasts, keratinocytes, macrophages, neutrophils, lymphocytes, endothelial cells, osteoclasts and osteoblasts, can destroy the peri-implant and periodontal tissues ${ }^{17}$. Moreover, an intense inflammatory process is mediated by cytokines which point to different cell types and stimulating the production of prostaglandins and matrix metalloproteinases, which are associated with bone and connective tissue breakdown ${ }^{18}$. The cluster phenomenon supports the evidence that individual characteristics play an important role in transcription of these inflammatory mediators and may influence the osseointegration success. Some studies show the influence of genetic polymorphisms in inflammatory mediators in implant loss. Cosyn et al. ${ }^{19}$ (2016) demonstrated that the IL-1B $(+3954)$ gene polymorphism affect osseointegration, beside previous studies not found evidence ${ }^{20}$. The genotype $2 / 2$ of IL1RN polymorphism and the C allele of IL-4 polymorphism was associated with susceptibility to dental implant $\operatorname{loss}^{20,21}$. In nonsmokers, have been show that a polymorphism in the promoter region of MMP-1 and MMP-8 gene is strongly associated with the early implant loss ${ }^{5-7}$. Our group suggested that haplotype G-1607GG and A-519G of MMP-1 may be associated with the osseointegration process ${ }^{6}$.

However, many others studies found no significant association between dental implant loss and polymorphism in inflammatory mediators such as MMP-9, IL-1, IL-2, IL-6, IL10, TNF-A, TGF-B, VNTR, and others ${ }^{5,20-23}$. In this study, the $-16125 \mathrm{~A} / 6 \mathrm{~A}$ polymorphism in the promoter region of MMP3 gene was also not associated with early implant failure in non-smokers.

In meta-analysis studies ${ }^{24,25}$ point that is important methodological and study design restricted to validate the associations, even though it has been raised as one of the potential risk indicators.

Early implant failure in non-smokers have a reduced frequency. Nevertheless, smoking is a strong risk factor for early implant failure - smokers have a 3\% greater chance of losing an implant compared to non-smokers ${ }^{26}$, so studies that includes smokers would possibly mask the genetic influence. In this study, we observed a number of patients in the test group with reliable estimated statistical power, despite put out smokers. Others risk factors with age, status periodontal, and medically compromised were exclude or matched.

In osseointegration, as with any complex process seems to be a combination of several polymorphisms act synergistically significant risk that increases the susceptibility to failure. So, it is important to consider that this MMP-3 polymorphism may have their effects masked by polymorphisms in different regions of a gene or other genes involved with periodontal inflammatory mediators. However, to identify the influence of each allele, it is essential to analyze the relative contribution of each polymorphism.

Since MMP-3 activates the MMP-1 and polymorphism in MMP-1 was associated with implant loss, it seems important to assess the linkage disequilibrium between the polymorphisms of MMP-3 and MMP-1 which are located on chromosome $11 \mathrm{q} 22.3$ adjacent to each other. It seems to be of great value to understand osseointegration process and the mechanisms of functional compensation of the individual. In future studies of the investigation of polymorphisms in the MMP-3 gene, mainly in haplotype combination, remains to be considered regarding implant loss due to the importance of this gene in osseointegration.

To understand the complex osseointegration failure is important analyze haplotype frequencies and imbalances between various polymorphisms. It could be help in clinical investigation of individuals at high risk to implant loss and, in future, guide the development of individual therapeutics to increasing the implants success rates.

\section{Conclusion}

In conclusion, no associations were found between -1612 $5 \mathrm{~A} / 6 \mathrm{~A}$ polymorphisms of the MMP-3 gene promoter and early implant failure, suggesting that the presence of this polymorphism alone are not a genetic risk factor for predisposition to early implant loss. Therefore, the investigation of polymorphisms in the MMP-3 gene, mainly in haplotype combination, remains to be considered regarding implant loss due to the importance of this gene in osseointegration.

\section{Acknowledgement}

The authors wish to thank Professor Dr. Silvio Sanches Veiga for his assistances. This study was supported by the Fundação Araucária and CAPES

\section{References}

1. Holm-Pedersen $P$, Lang NP, Muller $F$. What are the longevities of teeth and oral implants? Clin Oral Implants Res. 2007 Jun;18 Suppl 3:15-9.

2. Chrcanovic BR, Albrektsson T, Wennerberg A. Reasons for failures of oral implants. J Oral Rehabil. 2014 Jun;41(6):443-76. doi: 10.1111/joor.12157. 
3. Porter JA, Von Fraunhofer JÁ. Success or failure of dental implants? A literature review with treatment considerations. Gen Dent. 2005 Nov-Dec;53(6):423-32; quiz 433, 446.

4. Weyant RJ, Burt BA. An assessment of survival rates and within-patient clustering of failures for endosseous oral implants. J Dental Res. 1993 Jan;72(1):2-8.

5. Santos MC, Campos M, Souza AP, Trevilatto PC, Line SR. Analysis of MMP-1 and MMP-9 promoter polymorphisms in early osseointegrated implant failure. Int J Oral Maxillofac Implants. 2004 Jan-Feb;19(1):38-43.

6. Leite MFF, Santos MCLG, Souza AP, Line SRP. Osseintegrated implant failure associeted with MMP-1 promoter polymorphisms (-1607 and -519). Int J Oral Maxillofac Implants. 2008 Jul-Aug;23(4):653-8.

7. Costa-Junior FR, Alvim-Pereira CC, Alvim-Pereira F, Trevilatto PC, de Souza AP, Santos MC. Influence of MMP-8 promoter polymorphism in early osseointegrated implant failure. Clin Oral Investig. 2013 Jan;17(1):311-6. doi: 10.1007/s00784-012-0699-z.

8. Cauwe B, Van den Steen PE, Opdenakker G. The biochemical, biological, and pathological kaleidoscope of cell surface substrates processed by matrix metalloproteinases. Crit Rev Biochem Mol Biol. 2007 May-Jun;42(3):113-85.

9. Ramseier CA, Eick S, Brönnimann C, Buser D, Brägger U, Salvi GE. Host-derived biomarkers at teeth and implants in partially edentulous patients. A 10-year retrospective study. Clin Oral Implants Res. 2016 Feb;27(2):211-7. doi: 10.1111/clr.12566.

10. Johnson JL, Dwivedi A, Somerville M, George SJ, Newby AC. Matrix metalloproteinase (MMP)-3 activates MMP-9 mediated vascular smooth muscle cell migration and neointima formation in mice. Arterioscler Thromb Vasc Biol. 2011 Sep;31(9):e35-44. doi: 10.1161/ ATVBAHA.111.225623.

11. Woessner J. Matrix metalloproteinases and their inhibitors in connective tissue remodeling. FASEB J. 1991 May;5(8):2145-54.

12. Leong DJ, Gu XI, Li Y, Lee JY, Laudier DM, Majeska RJ, et al. Matrix metalloproteinase- 3 in articular cartilage is up-regulated by joint immobilization and suppressed by passive joint motion. Matrix Biol. 2010 Jun;29(5):420-6. doi: 10.1016/j.matbio.2010.02.004

13. Ito A, Mukaiyama A, Itoh $Y$, Nagase $H$, Thogersen IB, Enghild JJ, et al. Degradation of interleukin 1 beta by matrix metalloproteinases. J Biol Chem. 1996 Jun 21;271(25):14657-60.

14. Astolfi CM, Shinohara AL, Da Silva RA, Santos MC, Line SR, De Souza AP. Genetic polymorphisms in the MMP-1 and MMP-3 gene may contribute to chronic periodontitis in a Brazilian population. J Clin Periodontol. 2006 Oct;33(10):699-703.

15. Aidar M, Line SR. A simple and cost-effective protocol for DNA isolation from buccal epithelial cells. Braz Dent J. 2007;18(2):148-52.

16. Schneider S, D Roessli, L Excoffier. Arlequin v.2.000: software for population genetics data analysis. User manual: ver. 2.000. Geneva, Switzerland: Genetics and Biometry Laboratory, University of Geneva; 2000.

17. Seymour GJ, Gemmell E, Lenz LJ, Henry P, Bower R, Yamazaki K. Immunohistologic analysis of the inflammatory infiltrates associated with osseointegrated implants. Int J Oral Maxillofac Implants. 1989 Fall;4(3):191-8.

18. Greenstein G, Hart TC. Clinical utility of a genetic susceptibility test for severe chronic periodontitis: a critical evaluation. J Am Dent Assoc. 2002 Apr;133(4):452-9; quiz 492-3.

19. Cosyn J, Christiaens V, Koningsveld V, Coucke PJ, De Coster P, De Paepe A, et al. An Exploratory Case-Control Study on the Impact of IL-1 Gene Polymorphisms on Early Implant Failure. Clin Implant Dent Relat Res. 2016 Apr;18(2):234-40. doi: 10.1111/cid.12237.

20. Montes CC, Alvim-Pereira F, De Castilhos BB, Sakurai ML, Olandoski M, Trevilatto PC. Analysis of the association of IL1B $(C+3954 T)$ and IL1RN (intron 2) polymorphisms with dental implant loss in a Brazilian population. Clin Oral Implants Res. 2009 Feb;20(2):208-17. doi: 10.1111/j.1600-0501.2008.01629.x.

21. Pigossi SC, Alvim-Pereira F, Alvim-Pereira CC, Trevilatto PC, ScarelCaminaga RM. Association of interleukin 4 gene polymorphisms with dental implant loss. Implant Dent. 2014 Dec;23(6):723-31. doi: 10.1097/ ID.0000000000000157.

22. Campos MI, Godoy dos Santos MC, Trevilatto PC, Scarel-Caminaga RM, Bezerra FJ, Line SR. Interleukin-2 and interleukin-6 gene promoter polymorphisms, and early failure of dental implants. Implant Dent. 2005 Dec;14(4):391-6.

23. Gurol C, Kazazoglu E, Dabakoglu B, Korachi M. A comparative study of the role of cytokine polymorphisms interleukin-10 and tumor necrosis factor alpha in susceptibility to implant failure and chronic periodontitis. Int J Oral Maxillofac Implants. 2011 Sep-Oct;26(5):955-60.

24. Liao J, Li C, Wang Y, Ten M, Sun X, Tian A, et al. Meta-analysis of the association between common interleukin-1 polymorphisms and dental implant failure. Mol Biol Rep. 2014 May;41(5):2789-98. doi: 10.1007/ s11033-014-3133-6.

25. Dereka X, Mardas N, Chin S, Petrie A, Donos N. A systematic review on the association between genetic predisposition and dental implant biological complications. Clin Oral Implants Res. 2012 Jul;23(7):775-88. doi: 10.1111/j.1600-0501.2011.02329.x.

26. Esposito M, Hirsch JM, Lekholm U, Thomsen P. Biological factors contributing to failures of osseointegrated oral implants. (I). Success criteria and epidemiology. Eur J Oral Sci. 1998 Feb;106(1):527-51. 